\title{
FORMAÇÃO DE PROFESSORES: UMA EXPERIÊNCIA NO ESTÁGIO SUPERVISIONADO EM GEOGRAFIA
}

\author{
Gabriela Alexandre Custódio ${ }^{1}$ \\ Luiz Martins Junior ${ }^{2}$
}

\section{INTRODUÇÃO}

Os alunos concluintes dos cursos de Licenciatura em Geografia, têm como última etapa de sua formação a prática de estágio supervisionado, que geralmente contempla o exercício docente em escolas de ensino fundamental e médio. Etapa que se mostra, ao mesmo tempo, de extrema importância para a formação do futuro professor e um desafio, tendo em vista as dúvidas, incertezas e inseguranças que o início da profissão docente traz.

Nesse contexto, este trabalho traz as etapas e os resultadosdas experiências vivenciadas por formandos de Licenciatura em Geografia da Universidade da Região de Joinville - UNIVILLE.E traz como objetivo compreender o papel que as experiências e o saber profissional do professor da escola básica possui na formação dos estagiários e futuros professores de Geografia. Para tanto, este estudocontemplaas atividades teóricas e práticasdo estágio supervisionado em Geografia, realizadasem duas turmas de ensino médio, na Escola Estadual de Educação Básica Nereu Ramos, localizada no município deltapoá/SC, do segundo semestre de 2015.

Tal relato traz como base o processo de formação docente e os conhecimentos que fazem parte do repertório do professor. Tal abordagem, deve-se ao fato de se compreender que o processo de formação do saber docente se inicia com as primeiras experiências vivenciadas pelo professor e se mantém em transformação durante toda a vida profissional do educador.

Dessa forma, a partir da valorização dos saberes que fazem parte da prática profissional docente ecom base emum conhecimento construído a partir das

\footnotetext{
${ }^{1}$ Universidade Federal de Santa Catarina. gabialexandre27@gmail.com

2Universidade Federal de Santa Catarina. luizmartins.jr@hotmail.com
} 
experiências cotidianas do professor, é que se pretendeobter os subsídios necessários para efetivação de uma educação geográfica em que o aluno é colocado no papel de protagonista do processo de construção do próprio conhecimento.

\section{O PROCESSO DE FORMAÇÃO DE PROFESSORES: OS SABERES E PRÁTICAS DOCENTE}

Enquanto alunos da disciplina de "Prática de Ensino de Geografia", muitos dos futuros professores entram pela primeira vez em sala de aula como professores, uma etapa da formação docente que gera muitas dúvidas e insegurança nos profissionais em formação. Pois, como destacam Saiki e Godoi (2007), esse é um processo não deveria ser realizado apenas para o cumprimento da grade curricular, mas sim, deve ser conduzido de forma contextualizada e comprometido com a transformação social, unindo formação profissional e pessoal, com responsabilidade individual e social.

Para o desenvolvimento das atividades a serem realizadas na prática de ensino, as experiências e os conhecimentos adquiridos durante a graduação pelos alunos são extremamente importantes, tendo em vista que se serão os subsídios teóricos e metodológicos necessários à elaboração dos recursos e das técnicas utilizados em sala, como também, para o referencial no exercício de ensinar. Porém, a reestruturação didática dos conhecimentos acadêmicos para alunos da educação básica não é tarefa fácil, sobretudo quando o professor ainda não passou por experiências anteriores.

Nesse sentido, umas dos primeiros desafios do professor é saber conceber a Geografia ora como ciência, ora como disciplina, tendo claro que mesmo se tratando de um conhecimento único, os objetivos são distintos e por isso devem ser tratados de forma diferenciada. Como lembra Cassab (2009), é necessário reconhecer a distância que existe entre a Geografia acadêmica e a Geografia trabalhada nas escolas. Uma distância necessária, tendo em vista que as escolas trabalham com um público específico e com objetivos diferenciados. Da relação entre o conhecimento científico e o escolar, surge o desafio de compreender as particularidades existentes entre métodos distintos de um saber único, em que o conhecimento escolar não deve ser entendido como uma simplificação, mas como 
uma forma específica de tratar o conhecimento geográfico construído em bases científicas.

Ou seja, ter acesso e dominar os conhecimentos que darão suporte à tarefa docente, mostra-se a forma mais de eficaz de transformarprofessores e alunos os verdadeiros protagonistas no processo de ensino e aprendizagem. Para tanto, Passini (2007) lembrada importância que o Estágio Curricular Supervisionado tem para a formação do futuro professor e, consequentemente para sua prática em sala de aula. Como destaca autora, o que ensinar e como ensinar continuam sendo objetos de discussão nas aulas de Prática de Ensino de Geografia, e é durante esse processo que o estagiário aprenderá como planejar, desenvolver e executar uma aula, com base nas experiências vividas e com supervisão do professor regente da disciplina de prática.

Nesse sentido, Martins (2016) destaca que o estágio curricular supervisionado passa a ser considerado um espaço interdisciplinar de formação, com a finalidade de proporcionar maior conhecimento da realidade profissional, através de um processo de estudo, análise, problematização e reflexão sobre a realidade daprática docente. Pois,este encontro é um momento favorável à açãoreflexão-ação do exercício profissional, constituindo-se em um espaço privilegiado de formação.

Contudo, é importante destacar que o fim do período do estágio supervisionado não significa o fim do processo de forção do professor, mas o início de uma trajetória que deverá ser marcadapela atualização constante dos conhecimentos, pelo aperfeiçoamento das práticas e o aprimoramento experiências mas, sobretudo, pela preocupação em aprender sempre.

Nesse sentido, aplicar os conhecimentos que foram adquiridos durante a formação e ao longo da carreiradocente tende a favorecer o exercício da profissão, pois possibilita ao professor conhecer cada vez melhor as necessidades de cada aluno e, consequentemente, conduzir um processo de ensino e aprendizagem que atinja o objetivo de contribuir para o desenvolvimento intelectual e pessoal dos estudantes.

Sobre os conhecimentos que são agregados pelos professor em seu repertório profissional, Tardif (2011) traz que sãosaberes que podem ser definidos com plurais, formados pela amálgama, mais ou menos coerente, dos saberes 
oriundos da formação profissional e de saberes disciplinares, curriculares e experienciais (2011a, p. 36).

Esses são conhecimentos construídos ao longo da vida do professor, com início em sua formação inicial, e não tem fim. Pois é na formação continuada e, principalmente, na prática do fazer diário que o professor adquire toda a experiência e os conhecimentos necessários para lidar com as situações comuns do dia-a-dia de sala de aula e, também, buscar soluções para as situações inesperadas.

Ou seja, ser professor é ir além da simples reprodução de conteúdos e conhecimentos que foram previamente adquiridos em processos de formação. Ser professor é ser sujeito ativo do processo de ensino e aprendizagem, participante de uma construção que dever ser bidirecional, na medida em deve ser baseada na troca de conhecimentos e experiências entre alunos e professores.

Do trabalho conjunto, advêm os resultados almejados e na troca de experiências é que todos saem ganhando. O professor que ensina aprende e os alunos que aprendem também ensinam. A ação do professor deve ser voltada ao movimento, à provocação na tentativa de reciprocidade intelectual entre os elementos da ação educativa. Professor e alunos coordenando ideias e reorganizando-as (HOFFMAN, 2003).

Nessa lógica, Tardif (2011b) enfatiza que no processo de ensino e aprendizagem os professores são sujeitos ativos e suas práticas não são somente um espaço de saberes provenientes da teoria, mas também um espaço de produção de saberes específicos oriundos dessa mesma prática. E completamos, são resultados da interação, do convívio, das trocas estabelecidas entre os diferentes sujeitos do processo, em especial alunos e professores.

Como lembra Cavalcanti (2010), quando se discute o papel do professor ao ensinar Geografia na educação básica, é importante entender que as relações estabelecidas entre professores e alunos não são puramente cognitivas e racionais, nem são pré-estabelecidas e determinadas pelos papéis que cada um cumpre no processo. Relações abertas, dialógicas, negociadas, sem papéis sociais/profissionais cristalizados e fechados são de fundamental importância para a motivação de ambos os lados, em um processo em constante construção e transformação.

Quando se pensa no trabalho desempenhado pelo professor, baseado em referências de um saber docente constituído na experiência, é consenso entre os 
estudiosos da área do ensino a importância atribuída à atividade intelectual no exercício de ser professor. Como lembra Cavalcanti (2012), a atividade intelectual está impregnada em todas as dimensões da vida do professor, o que significa dizer que ele está sempre aprendendo, sempre ensinando, porque se coloca na vida como sujeito da aprendizagem. Ou seja, o professor é um intelectual, autor do seu trabalho, que pesquisa sobre o que faz e não simplesmente executa, na prática, a teoria de outros.

Dessa forma, entende-se que ser mediador parte do processo de ensino e aprendizagem não é apenas ser transmissor de informações, mas um construtor do conhecimento, em que as situações excepcionais do cotidiano não devem vistas apenas como dificuldades, mas como momentos para a reflexão e troca de experiências que fazem parte do processo de constituição do saber docente. Tais experiências, agregadas ao processo educacional, podem beneficiar 0 desenvolvimento e a implementação do fazer diário do professor, o que, consequentemente, tende a favorecer a construção de um saber docente que prioriza a construção e a efetivação de um trabalho de qualidade focado na formação dos alunos.

\section{METODOLOGIA}

Para o desenvolvimento das atividades a serem realizadas na prática de ensino, as experiências e os conhecimentos adquiridos durante a graduação são subsídios teóricos e metodológicos importantes para a preparação e organização dos recursos utilizados em sala, assim como, para o exercício de ensinar. Porém, a mudança do contexto acadêmico para o escolar não é processo fácil, principalmente quando se passa a conhecer e a vivenciar os desafios atuais da educação básica no Brasil.

Nesse contexto, operíodo de estágio supervisionadopode ser considerado, antes de mais nada,um momento de descobertas, em que o contexto escolar e os sujeitos que dão vida a esses espaços são apresentados à rotina do futuro professor. Experiência essa que pode servivenciada pelos estagiários desde 0 início das observações, realizadas na escola no primeiro semestre de 2015, na Escola Estadual de Ensino Básico Nereu Ramos, no município de Itapoá, Santa Catarina. 
O momento reservado às observações, que ocorreu nas aulas de Geografia, nas turmas de ensino médio do período vespertino e noturno, teve como intuito conhecer e reconhecer as múltiplas práticas de trabalho realizadas pela professora das turmas, a partirdas discussões, da participação, eda relação alunos/professora.

Fez parte do período de preparação das aulas a escolha dos conteúdos que seriam trabalhados durantes as aulas. Essa foi uma das etapas da organização da parte prática do estágio, queexigiu cuidado e atenção do estagiário, pois os conteúdos escolhidos deveriam estar de acordo com o planejamento anual da disciplina e proporcionar aos alunos os subsídios necessários para realizar uma análise crítica sobre a temática escolhida, que tratou das questões ambientais da atualidade e o desenvolvimento sustentável.

Após o planejamento e organização das aulas, iniciou-se a parte prática do estágio supervisionado, que se dividiu em quatro encontros. A primeira aula constituiu na apresentação dos objetivos do plano de trabalho, que se seguiu com a realização de uma análise sobre os conhecimento prévios dos alunos acerca da temática proposta, a partir de uma discussão preliminar.

No segundo encontro, retomou-se a discussão iniciada na primeira aula e se ampliou o debate com base no referencial teórico proposto, buscando-se discutir os problemas ambientais da atualidade e as possibilidades de minimização dos impactos causados pela exploração desordenada dos recursos naturais, na perspectiva do desenvolvimento sustentável.

No terceiro encontro, realizou-se uma atividadeem que os alunos tiveram que elaborar uma correspondência, uma carta em que tinham que relatar informações com os seguintes critérios: escolher um país e realizar uma pesquisa em sites da internet, com o intuito de observar questões relacionadas à exploração ambiental, às práticas voltadas ao desenvolvimento sustentável, bem como destacar os aspectos geográficos físicos, culturais e sociais nos diferentes contextos.

No último encontro, em um total de oito aulas, os alunos puderam trocar as cartas e a experiência vivenciadas. Como atividade de encerramento, foi realizado um seminário para discussão dos resultados e avaliação do processo. Durante o seminário, foram discutidos princípios, valores, responsabilidade social e 
práticas ecológicas que podem ser o diferencial na busca pela manutenção da qualidade de vida para a atual e para as futuras gerações.

\section{RESULTADOS E DISCUSSÕES}

Após o período de reconhecimento das turmas, partiu-se para a parte prática do estágio. Nesse contexto, as aulas foram orientadas no sentido de apresentar aos alunos projetos de preservação e desenvolvimento sustentável ao redor do mundo e, ao fim do processo, pensou-se na elaboração de uma atividade avaliativa em que os alunos teriam que elaborar uma correspondência (carta) para um colega de turma relatando suas observações e opiniões sobre a pesquisa realizada.

A proposta de trabalho apresentada para as turmas participantes, durante o período de estágio supervisionado,teve como objetivo tornar os alunos protagonistas do processo de construção do próprio conhecimento. Nesse sentido, o estímulo à argumentação, à exposiçãodos conhecimentos préviossobre questões ambientais e práticas sustentáveis oportunizouque os estudantes trouxessem suas opiniões e críticas sobre a realidade, bem como, fez com que repensassem o papel e a responsabilidade de cada um enquanto defensores de práticas voltadas à preservação ambiental.

Na discussão final, os alunos apresentaram argumentos e considerações importantes sobre a temática ambiental, pois perceberam as divergências e as fragilidades que cercam tal discussão nos diferentes contextos pesquisados. Como itens e sugestões trazidos pelos alunos, destacam-se os projetos com materiais recicláveis nas unidades escolares; a promoção e divulgação de informações nas escolas e outras entidades, como em centros de saúde, centros comunitários; palestras de educação ambiental; projetos sustentáveis nas escolas e comunidades; entre outros.

Ao se ter como referência um processo de ensino e aprendizagem que parte das experiências trazidas pelos alunos, a busca por metodologiasque supram as necessidades e as expectativas de todos deve ser uma das principais prioridades da prática docente. Para tanto, os educadores devem trazer para a sala de aula os subsídios teóricos e recursos necessários para auxiliar no desenvolvimento da autonomia de todos os estudantes. 
Como lembra Callai (2003), no processo concreto de construção do conhecimento, o aluno deverá aproveitar os conteúdos da Geografia que são mediados pelo professor, a fim de se tornar um cidadão, no sentido real da palavra. Para tanto, para que o saber ensinado se efetive em conhecimento construído pelos alunos, os professores não devem conduzir o processo de ensino e aprendizagem de forma solta e descontextualizada, as referências precisam ser concretas e significativas a fim de que a construção do saber se realize a partir da troca, do trabalho conjunto de ambos.

Nesse contexto, é que se insereo uso das tecnologias como instrumento útil capaz conduzir o processo de ensino e aprendizagem em Geografia, que ofereça possibilidades para superar as barreiras impostas pelos métodos tradicionais de ensino, para que se possa contextualizara realidade e o dia-a-dia dos alunos, por meio de recursos e informações que, de forma geral, ainda estão distantes do convívio de alunos e professores.

Por isso, destaca-se a importância de se estimular atividade que priorizem a comunicação e o debate entre os pares em sala de aula, pois são inciativas que tendem a estimular asocialização de ideias, a verbalização das opiniões, manifestadas por meio da leitura e da escrita, comopráticas que devem ser prioridade no processo de ensino e aprendizagem em Geografia.

De acordo com o planejamento, o desenvolvimento da atividade em grupo ocorreu dentro do previsto,tendo em vista que a turma apresentou domínio no uso das ferramentas de pesquisa, o que resultou na obtenção dos objetivos propostos, com destaque à autonomia e ao protagonismo que se fez presente durantetodo o processo de ensino e aprendizagem.

Sendo assim, observou-se que os objetivos propostosofereceram os subsídios necessáriospara que os alunos e alunas compreendessem o espaço em que vivem, fazendo com que eles pudessem observar, descrever e criticaros problemas ambientais da realidade, bem como,reavaliar o papel social e político de cada um na sociedade.

Operíodo da regência foi uma experiência e uma oportunidade para que os acadêmicos, enquanto futuros profissionais da educação, pudessem compreender a responsabilidade e o compromissoque o processo de mediação do conhecimento requer do professor $\mathrm{O}$ que significa dizer, que a profissão docente, 
mais do que apenas ensinar, é uma profissão que se renova sempre, num continuum processo de construção e reformulação dos saberes docentes.

\section{CONSIDERAÇÕES FINAIS}

Encerra-se esta análise com a certeza de que foram esses,momentos de aprendizagem e que reforça a importância da disciplina de Prática de Ensino para a formação de futuros professores, em que muitostêm sua iniciação profissional. Nesse sentido, a experiência em estar em sala de aula mostra que, acima de tudo, a profissão docente se constitui em um eterno exercício de apre(e)nder.

Como responsável pela condução das aulas, coube aos estagiários a tarefa de pensar a forma mais adequada de levar às informações aos alunos. Desde a preparação dos planos de aula, da organização das atividades, ao desenvolvimento do material didático utilizado, todos os momentos de intervenção foram marcados pelo anseio de contemplar as especificidades da turma. Dessa forma, destaca-se a importância das aulasserem voltadas à diversidade presente no contexto escolar, como inciativa que demonstra o envolvimento dos professores com efetivação de uma educação geográfica realmente significativa.

Para que isso fosse possível, o período de estágio foi um momento de articular e inter-relacionar teoria com a prática, em que se pode aprender estratégias e observar a relação de trabalho e convívio entre alunos e professores. Relação esta que deve ser baseada, muito mais, na troca de experiências do que na transmissão de conteúdos e informações. De tal modo, como destaca Piconez (1991), o estágio é um componente teórico-prático, isto é, possuí uma dimensão ideal, subjetiva, teórica, articulada com as posturas educacionais, e uma dimensão real, material, social e prática, própria do contexto escolar.

Tal contexto, evidenciou a necessidade de o aluno ser visto como o sujeito da aprendizagem, no qual deve ser estimulado e desafiado durante todo o processo. Para tanto, o professor deve assumir o papel de mediador, em que as dificuldades e as dúvidas devem ser vistas como o caminho para que uma aprendizagem realmente significativa se efetive.

Nesse sentido, compreende-se que é da junção dos conhecimentos trazidos pelos alunos com o saber ensinado no contexto escolar que surge o 
caminho para uma aprendizagem construída na troca de experiências entre professores e alunos, em uma relação ativa e dialógica, em que os saberes são construídos e reconstruídos mutuamente. Pois, é do trabalho conjunto, advêm os resultados almejados e na troca de experiências é que todos saem ganhando. $O$ professor que ensina aprende e os alunos que aprendem também ensinam.

Chegou-se ao final dessa etapa com a sensação de dever cumprindo, pois os objetivos propostos para as aulas do estágio supervisionado foram atingidos. Talexperiência, mostrou-seuma prévia dos desafios futuros dos professores recémformados em Geografia, que certamente, servirão de estímulo para que se busque sempre a concretização de uma educação mais justa e de qualidade para todos.

\section{REFERÊNCIAS}

CALLAI, H. C. O Ensino de Geografia: recortes espaciais para análise. In: org. CASTROGIOVANNI... [et al.]. Geografia em sala de aula: práticas e reflexões. - 4 ed. Porto Alegre: ed. da UFRGS/Associação de Geógrafos Brasileiros - Seção Porto Alegre, 2003. p. 57-63.

CASSAB, C. Reflexões sobre o ensino de Geografia. Geografia \& Pesquisa. Santa Maria, v. 13, n. 1, p. 43-50, 2009.

CAVALCANTI, L. de S. A Geografia e a realidade escolar contemporânea: avanços, caminhos e alternativas. IN: Anais do I Seminário Nacional: currículo em movimento - perspectivas atuais. Belo Horizonte, Nov. de 2010. p. 1-15.

A formação profissional: princípios e propostas para uma atuação docente crítica. In CAVALCANTI, L. de S. O ensino de Geografia na escola. Campinas, SP: Papirus, 2012, p. 13-38 - (Coleção Magistério: formação e trabalho pedagógico).

HOFFMANN, J. Avaliação mediadora: uma prática em construção da pré-escola à universidade. Porto Alegre: Ed. Mediação, 20 ed. 2003.

LOPES. C. S. A formação e o desenvolvimento da profissionalidade do professor de Geografia. IN: Olhar do professor, Ponta Grossa, 13(1): 47-66, 2010.

MARTINS, Rosa E. M. W. O estágio na licenciatura em geografia como um espaço de formação compartilhada. In: LAWAL, Ivani Teresinha; CLEMENT, Luiz. (Org.)

Relatos e reflexões sobre estágio curricular supervisionado: cursos de licenciatura da UDESC. Goiânia: C\&A Alfa Comunicação, 2016. 
PASSINI, E. Y. Convite para inventar um novo professor. In: PASSINI, Elza Yasuko; PASSINI, Romão; MALYSZ, Sandra T. (Org.). Prática de ensino de Geografia e estágio supervisionado. São Paulo: Contexto, 2007, p.32-51.

PICONEZ, S.C.B. A Prática de ensino e o estágio supervisionado: a aproximação da realidade escolar e a prática da reflexão. In: PICONEZ, S. C.B (Org.). A prática ensino e estágio supervisionado. Campinas: Papirus, 1991.

SAIKI, Kim; GODOI, Francisco Bueno de. A Prática de ensino e o estágio Supervisionado. In: PASSINI, Elza Yasuko; PASSINI, Romão; MALYSZ, Sandra T. (Org.). Prática de ensino de Geografia e estágio supervisionado. São Paulo: Contexto, 2007, p.26-31.

TARDIF, M. Os professores diante do saber: esboço de uma problemática do saber docente. In: TARDIF, M. Saberes docentes e formação profissional. 12 ed. Petrópolis, RJ: Vozes, 2011a. p. 31-55.

TARDIF, M. Os professores enquanto sujeitos do conhecimento. In: TARDIF, M. Saberes docentes e formação profissional. 12 ed. Petrópolis, RJ: Vozes, $2011 \mathrm{~b}$. p. 227-244. 